\title{
Multilocus Variable-Number-Tandem-Repeats Analysis (MLVA) distinguishes a clonal complex of Clavibacter michiganensis subsp. michiganensis strains isolated from recent outbreaks of bacterial wilt and canker in Belgium
}

\author{
Joanna Zaluga ${ }^{1 *}$, Pieter Stragier ${ }^{1}$, Johan Van Vaerenbergh ${ }^{2}$, Martine Maes ${ }^{2}$ and Paul De Vos ${ }^{1,3}$
}

\begin{abstract}
Background: Clavibacter michiganensis subsp. michiganensis $(\mathrm{Cmm})$ causes bacterial wilt and canker in tomato. $\mathrm{Cmm}$ is present nearly in all European countries. During the last three years several local outbreaks were detected in Belgium. The lack of a convenient high-resolution strain-typing method has hampered the study of the routes of transmission of $\mathrm{Cmm}$ and epidemiology in tomato cultivation. In this study the genetic relatedness among a worldwide collection of $\mathrm{Cmm}$ strains and their relatives was approached by gyr $B$ and $d n a A$ gene sequencing. Further, we developed and applied a multilocus variable number of tandem repeats analysis (MLVA) scheme to discriminate among $\mathrm{Cmm}$ strains.

Results: A phylogenetic analysis of gyrB and dnaA gene sequences of $56 \mathrm{Cmm}$ strains demonstrated that Belgian Cmm strains from recent outbreaks of 2010-2012 form a genetically uniform group within the Cmm clade, and $\mathrm{Cmm}$ is phylogenetically distinct from other Clavibacter subspecies and from non-pathogenic Clavibacter-like strains. MLVA conducted with eight minisatellite loci detected 25 haplotypes within $\mathrm{Cmm}$. All strains from Belgian outbreaks, isolated between 2010 and 2012, together with two French strains from 2010 seem to form one monomorphic group. Regardless of the isolation year, location or tomato cultivar, Belgian strains from recent outbreaks belonged to the same haplotype. On the contrary, strains from diverse geographical locations or isolated over longer periods of time formed mostly singletons.

Conclusions: We hypothesise that the introduction might have originated from one lot of seeds or contaminated tomato seedlings that was the source of the outbreak in 2010 and that these $\mathrm{Cmm}$ strains persisted and induced infection in 2011 and 2012. Our results demonstrate that MLVA is a promising typing technique for a local surveillance and outbreaks investigation in epidemiological studies of $\mathrm{Cmm}$.
\end{abstract}

Keywords: Clavibacter, MLVA, Bacterial typing, Epidemiology, Bacterial wilt and canker, Plant pathogen

\footnotetext{
* Correspondence: joanna.zaluga@ugent.be

'Laboratory of Microbiology, Department of Biochemistry and Microbiology,

Ghent University, K.L. Ledeganckstraat 35, B-9000 Gent, Belgium

Full list of author information is available at the end of the article
} 


\section{Background}

Clavibacter michiganensis subsp. michiganensis, a Gram positive bacterium, is the causative agent of bacterial canker and wilting, one of the most destructive bacterial diseases in tomato [1]. Contaminated tomato seeds are considered to be the main source of infection. The bacterium survives for a long period of time in seeds, soil and plant debris [2,3]. Every year, new or reoccurring outbreaks are detected causing substantial economic losses worldwide [4]. Bacterial canker was described for the first time in 1905 in Michigan, USA, and since that moment it has been reported in nearly all tomato growing areas of the world [3]. Difficulties in controlling the spread of the pathogen, the lack of resistant tomato varieties and severity of disease symptoms led to the classification of $\mathrm{Cmm}$ as quarantine organisms. $\mathrm{Cmm}$ is listed as an A2 quarantine pest by the European and Mediterranean Plant Protection Organization (EPPO) [2] in Europe and in many countries all over the world [1].

The epidemiology and the population structure of $\mathrm{Cmm}$ in areas where outbreaks of $\mathrm{Cmm}$ are common remains scantily investigated and poorly understood. Recent studies describing outbreaks of $\mathrm{Cmm}$ in Europe and Asia [5-8] have shed some light on this issue. In Italy a clonal population of Cmm was responsible for the outbreak in 2007 [9]. A high homogeneity was also observed among strains isolated from 2002 to 2007 in Canary Islands suggesting a single introduction of the pathogen as a source of infection [6]. Primary infections in many countries were attributed to the introductions of contaminated tomato seeds and/or seedlings $[7,10]$. These findings indicate that seeds play an important role in long-distance spread of the pathogen. A direct link between tomato cultivar, year or place of isolation and Cmm type mostly could not be recognized $[6,8,9]$ except the outbreak in 2001 in Turkey where bacterial canker was detected only on one tomato cultivar 'Target' [11]. Interestingly, in Israel and Serbia Cmm strains showing the same haplotypes were repeatedly isolated from the same locations during several subsequent years $[7,10]$. Reoccurring outbreaks suggest that despite intensified efforts for eradication, reliable control of this disease remains an unattainable goal. The limited progress in improving its management is mainly due to the sporadic nature of the disease outbreaks and to limited and scattered epidemiological data. Therefore, access to an accurate, efficient and cost-effective strain typing technique could be very useful.

Bacterial typing techniques are applied to quickly and reliably differentiate closely related strains in an epidemiological survey, to determinate the relatedness among the strains and to track their origin and pathways of spread. Over the past decades a variety of different typing methods have been developed to generate strain-specific patterns. They are also applied for comprehensive investigation of bacterial population structure and dynamics. A range of methods has already been applied to study the diversity of Clavibacter, particularly to investigate $\mathrm{Cmm}$ strains. Rep-PCR (repetitive-element-based PCR), a relatively easy and fast technique, was shown to be of moderate utility [8], mainly because of the lack of a database and the rather low discriminatory power needed to study closely related strains. Moreover, rep-PCR is mostly not portable between different laboratories [12]. PFGE (pulsed-field gel electrophoresis of macro-restricted bacterial DNA), one of the oldest techniques used in epidemiology, is labor intensive and expensive but is still used as a gold standard in typing of some bacterial species $[10,13]$. PFGE was applied to study the diversity of $\mathrm{Cmm}$ strains from outbreaks in Serbia [7] and in Israel [10] where the results of PFGE showed similar resolution of those obtained by gene sequence analysis and rep-PCR, respectively. Also, AFLP, a high resolution molecular typing method was applied by De Leon and coworkers to study genetic diversity of $\mathrm{Cmm}$ strains from Canary Islands [6]. This technique generated more bands per strain and resulted in more reproducible and robust discriminatory clustering of the strains [6]. Highly reproducible multilocus sequence typing (MLST) was used to analyze $\mathrm{Cmm}$ population from Serbia. Cmm strains were divided into seven groups and the results were confirmed by PFGE analysis [7].

MLVA (Multiple-Locus Variable number tandem repeat Analysis) is a PCR-based typing technique that has been widely applied in medical microbiology [14]. It takes advantage of the inherent variability encountered in regions with a number of tandem repeats. The origin of the repetitive regions can be accounted to slipped strand mispairing events occurring during DNA duplication, in which repetitive regions are incorrectly copied resulting in deletion or insertion of one or several copies of the repeat [15]. PCR primers designed to board different VNTR (Variable Number of Tandem Repeats) regions in the genome can be easily combined in a multiplex PCR in an MLVA scheme. The differences between strains are assessed by the different lengths of the repeats visualized by gel electrophoresis or automated fragment analysis on a sequencer. From these sizes, the number of repeat units at each locus can be deduced. The resulting information forms a strain-specific numerical code which can be easily compared to a reference database. The MLVA technique was introduced to bacterial typing as a promising alternative or a complement to already existing typing methods such as AFLP, MLST, rep-PCR or PFGE. The discriminatory power of MLVA is generally higher than other standard typing techniques [16]. However, the final result is group dependent and can vary considerably between different bacterial species. VNTRs have been used to discriminate among individual strains within many foodborne pathogens with little genetic differences, including Escherichia coli O157:H7 [17] and Vibrio cholerae [18] 
and to study other important human pathogens, such as Neisseria gonorrhoeae [19], Streptococcus pneumoniae [20], and Mycobacterium tuberculosis [21]. MLVA has been extensively used for tracking transmissions of important human and animal pathogens [22,23] and for typing monomorphic bacterial pathogens including Bacillus anthracis [24] and Yersinia pestis [25]. To date, several MLVA schemes have been published on plant pathogens such as Xanthomonas citri pv. citri [31], X. oryzae pv. oryzicola [26], Pseudomonas syringae pv. maculicola and tomato [27], Xylella fastidiosa [28] and on fungi e.g. Aspergillus flavus [29], but not for Clavibacter subspecies. In plant pathogens, such as Xanthomonas arbolicola pv. pruni, MLVA was proposed as a complementary molecular typing method to AFLP, BOX and ERIC-PCR [30]. In the epidemiological study of pathotypes of Xanthomonas citri MLVA was compared to AFLP and insertion sequence ligation-mediated PCR (IS-LM-PCR) and was found the best method to describe the variations among strains originating from the same country or group of neighboring countries [31].

The objectives of this study were: 1 ) to characterize a Belgian population of $\mathrm{Cmm}$ strains by a newly developed MLVA scheme; 2) to compare its genetic variability with some strains of $\mathrm{Cmm}$ isolated in other countries; 3) to investigate whether the strains responsible for bacterial canker outbreaks in Belgium in 2010-2012 have one or several infection sources and 4) to assess the genetic relatedness of the Cmm strains from Belgium by gyrB and dnaA gene sequence analysis.

\section{Methods}

\section{Bacterial strains}

The bacterial strains used in this study are listed in Table 1. The strains were obtained from the BCCM/LMG Bacteria Collection (Ghent, Belgium), the GBBC (ILVO Plant Clinic, Merelbeke, Belgium) and the PD collection (Wageningen, The Netherlands). The Clavibacter strain subset consisted of five type strains Cmm LMG $7333^{\mathrm{T}}$ (species type strain), Clavibacter michiganensis subsp. nebraskensis (Cmn) LMG $5627^{\mathrm{T}}$, Clavibacter michiganensis subsp. sepedonicus (Cms) LMG $2889^{\mathrm{T}}$, Clavibacter michiganensis subsp. insidiosus (Cmi) LMG $3663^{\mathrm{T}}$, Clavibacter michiganensis subsp. tessellarius (Cmt) LMG $7294^{\mathrm{T}}$, two non-pathogenic Clavibacter-like strains and fifty five $\mathrm{Cmm}$ originating from Belgian outbreaks and other geographical locations. Twenty three $\mathrm{Cmm}$ strains were sampled from symptomatic tomato plants in fields and greenhouses in northeast Belgium. They were isolated from five different tomato cultivars and seven different locations, in the period February 2010 till February 2012 (Table 1). Clavibacter-like isolates from tomato seed are phenotypically similar to $\mathrm{Cmm}$ in the common diagnostic semi-selective media and are identified as $\mathrm{Cmm}$ in the standard tests but are non-pathogenic to tomato [32,33]. They were isolated according to the current method for detection of $\mathrm{Cmm}$ in tomato seed recommended by International Seed Federation (ISF) [34]. The strains were cultured aerobically on MTNA (mannitol, trimethoprim, nalidixic acid, amphotericin) medium without antibiotics [35] at $25^{\circ} \mathrm{C}$ for 24-48 h. Stock cultures were stored at $-80^{\circ} \mathrm{C}$ in Microbank ${ }^{\mathrm{TM}}$ beads (Pro-Lab Diagnostics, Canada).

\section{DNA extraction, amplification and sequencing}

Total genomic DNA was extracted according to the guanidium-thiocyanate-EDTA-sarkosyl method described by Pitcher et al. [36] which was adapted for Gram-positive bacteria by a pre-treatment with lysozyme $(5 \mathrm{mg} / \mu \mathrm{l}$ lysozyme in TE buffer). Amplification and sequencing primers are listed in Table 2. The expected amplicons were generated with the Qiagen Taq DNA polymerase kit (supplemented with a Q-Solution) and GeneAmp ${ }^{\circ}$ dNTP's (Applied Biosystems, Belgium) according to the manufacturer specifications and with primers from Sigma Aldrich (Belgium). Amplicons were purified using the Nucleofast ${ }^{\circ} 96$ PCR clean up membrane system (MachereyNagel, Germany). Sequencing PCR was performed in a total volume of $10 \mu \mathrm{l}$ with $3 \mu \mathrm{l}$ of a purified amplicon, $0.286 \mu \mathrm{l}$ of BigDye mixture (Terminator Cycle Sequencing Kit version 3.1, Applied Biosystems), 1x sequencing buffer and $1.2 \mu \mathrm{M}$ of each of the amplification primers listed in Table 2. The PCR program consisted of 30 cycles $\left(96^{\circ} \mathrm{C}\right.$ for $15 \mathrm{~s}, 35^{\circ} \mathrm{C}$ for $1 \mathrm{~s}, 60^{\circ} \mathrm{C}$ for $\left.4 \mathrm{~min}\right)$. Subsequently, the sequencing products were purified using the BigDye XTerminator Kit (Applied Biosystems) and analyzed on a 3130xl Genetic Analyzer (Applied Biosystems).

\section{Sequence analysis}

In the frame of the European project QBOL (Quarantine Barcoding Of Life) we developed a $\operatorname{gyr} B$ barcode that was proven suitable to identify members of the genus Clavibacter at the subspecies level (http://www.q-bank.eu/) [32]. Moreover, gyrB gene was used in MLST schemes developed to type $\mathrm{Cmm}$ strains [7,33,37]. DnaA sequence was shown a good taxonomic marker to identify and classify plant pathogenic bacteria such as Clavibacter, Xanthomonas and Ralstonia [38]. The partial sequencing of $d n a A$ was successfully used to study genetic diversity of non-pathogenic Clavibacter-like strains and to identify members of the genus Clavibacter (J. Zaluga, data unpublished). The gyrB and $d n a A$ sequences were assembled with BioNumerics version 5.1 (Applied Maths, Belgium) and aligned using ClustalW [39]. GyrB sequences and $d n a A$ sequences were checked by amino acid translation with Transseq (http://www.ebi.ac.uk/Tools/emboss/ transeq/) and presence of the GyrB and DnaA protein domain was confirmed with BlastP [40]. DnaA and gyrB 
Table 1 Clavibacter strains included in the study

\begin{tabular}{|c|c|c|c|c|c|c|c|c|}
\hline $\mathrm{Nr}$ & Strain $\mathrm{nr}^{1}$ & $\mathrm{Name}^{2}$ & Host of isolation & Cultivar & Geographical $^{3}$ origin & Year of isolation & Alternative number & MLVA group $^{4}$ \\
\hline 1 & GBBC 283 & $\mathrm{Cmm}$ & Solanum lycopersicum & - & Belgium & 2007 & - & G \\
\hline 2 & GBBC $1082^{*}$ & $\mathrm{Cmm}$ & Solanum lycopersicum & Admiro & Belgium & 2011 & - & W \\
\hline 3 & GBBC 1083* & $\mathrm{Cmm}$ & Solanum lycopersicum & Admiro & Belgium & 2011 & - & W \\
\hline 4 & GBBC $1086^{*}$ & $\mathrm{Cmm}$ & Solanum lycopersicum & - & Belgium & 2011 & - & W \\
\hline 5 & GBBC 1389 & $\mathrm{Cmm}$ & Solanum lycopersicum & - & Belgium & 2012 & - & W \\
\hline 6 & GBBC $297^{*}$ & $\mathrm{Cmm}$ & Solanum lycopersicum & Growdena & Belgium (Berlaar) & 2010 & - & W \\
\hline 7 & GBBC $310^{*}$ & $\mathrm{Cmm}$ & Solanum lycopersicum & Growdena & Belgium (Berlaar) & 2010 & - & W \\
\hline 8 & GBBC 298* & $\mathrm{Cmm}$ & Solanum lycopersicum & Admiro & Belgium (Beveren) & 2010 & - & W \\
\hline 9 & PD 5734 & $\mathrm{Cmm}$ & Solanum lycopersicum & Adelaide & Belgium (Duffel) & 1998 & GBBC $178=$ LMG 26621 & E \\
\hline 10 & $\underline{\text { GBBC } 296^{*}}$ & $\mathrm{Cmm}$ & Solanum lycopersicum & Growdena & Belgium (Duffel) & 2010 & - & W \\
\hline 11 & GBBC $311^{*}$ & $\mathrm{Cmm}$ & Solanum lycopersicum & Growdena & Belgium (Duffel) & 2010 & - & W \\
\hline 12 & GBBC $316^{*}$ & $\mathrm{Cmm}$ & Solanum lycopersicum & Growdena & Belgium (Duffel) & 2010 & - & W \\
\hline 13 & GBBC $1060^{*}$ & $\mathrm{Cmm}$ & Solanum lycopersicum & Admiro & Belgium (Duffel) & 2010 & - & W \\
\hline 14 & GBBC 282 & $\mathrm{Cmm}$ & Solanum lycopersicum & Plaisance & Belgium (Geel) & 2007 & PD $5741=$ LMG 26626 & U \\
\hline 15 & GBBC 285 & $\mathrm{Cmm}$ & Solanum lycopersicum & Admiro & Belgium (Kontich) & 2008 & PD 5742 = LMG 26627 & I \\
\hline 16 & PD 1953 & $\mathrm{Cmm}$ & Solanum lycopersicum & Dombito & Belgium (Melsele) & 1990 & GBBC $100=$ LMG 26622 & G \\
\hline 17 & GBBC $1604^{*}$ & $\mathrm{Cmm}$ & Solanum lycopersicum & Growdena & Belgium (Melsele) & 2010 & - & W \\
\hline 18 & GBBC $301^{*}$ & $\mathrm{Cmm}$ & Solanum lycopersicum & Growdena & Belgium (Melsele), ng & 2010 & - & W \\
\hline 19 & GBBC $300^{*}$ & $\mathrm{Cmm}$ & Solanum lycopersicum & Growdena & Belgium (Melsele), og & 2010 & - & W \\
\hline 20 & GBBC $1064^{*}$ & $\mathrm{Cmm}$ & Solanum lycopersicum & Growdena & Belgium (Putte) & 2010 & - & W \\
\hline 21 & GBBC $1606^{*}$ & $\mathrm{Cmm}$ & Solanum lycopersicum & Levanzo & Belgium (Rijkevorsel) & 2010 & - & W \\
\hline 22 & PD 5737 & $\mathrm{Cmm}$ & Solanum lycopersicum & Concreto 622 & Belgium (Rumst) & 1984 & GBBC $103=$ LMG 26624 & J \\
\hline 23 & PD 5733 & $\mathrm{Cmm}$ & Solanum lycopersicum & Durinta & Belgium (Rumst) & 1996 & GBBC $150=$ LMG 26620 & $L$ \\
\hline 24 & GBBC $1609^{*}$ & $\mathrm{Cmm}$ & Solanum lycopersicum & DRW 7749 & Belgium (Rumst) & 2010 & - & W \\
\hline 25 & PD 5736 & $\mathrm{Cmm}$ & Solanum lycopersicum & Rianto & Belgium (St-Katelijne-Waver) & 1983 & GBBC $101=$ LMG 26623 & । \\
\hline 26 & GBBC $312^{*}$ & $\mathrm{Cmm}$ & Solanum lycopersicum & Growdena & Belgium (Waver) & 2010 & - & W \\
\hline 27 & GBBC $1061^{*}$ & $\mathrm{Cmm}$ & Solanum lycopersicum & Growdena & Belgium (Waver) & 2010 & - & W \\
\hline 28 & GBBC $1605^{*}$ & $\mathrm{Cmm}$ & Solanum lycopersicum & Bigdena & Belgium (Waver) & 2010 & - & W \\
\hline 29 & GBBC 303* & $\mathrm{Cmm}$ & Solanum lycopersicum & DRW 7749 & Belgium (Wervic) & 2010 & - & W \\
\hline 30 & GBBC $304^{*}$ & $\mathrm{Cmm}$ & Solanum lycopersicum & Bigdena & Belgium (Wervic) & 2010 & - & W \\
\hline 31 & GBBC $308^{*}$ & $\mathrm{Cmm}$ & Solanum lycopersicum & DRW 7749 & Belgium (Wervic) & 2010 & - & W \\
\hline 32 & PD 5753 & $\mathrm{Cmm}$ & Solanum lycopersicum & - & Algeria & 1985 & CFBP 2495 & Q \\
\hline 33 & LMG 5644 & $\mathrm{Cmm}$ & Solanum lycopersicum & - & Canada & 1982 & - & 0 \\
\hline
\end{tabular}


Table 1 Clavibacter strains included in the study (Continued)

\begin{tabular}{|c|c|c|c|c|c|c|c|c|}
\hline 34 & Cl01TF02 & $\mathrm{Cmm}$ & Solanum lycopersicum & - & Canary Islands (Tenerife) & 2003 & - & C \\
\hline 35 & GBBC 1077 & $\mathrm{Cmm}$ & Solanum lycopersicum & - & France & 2010 & - & W \\
\hline 36 & GBBC 1078 & $\mathrm{Cmm}$ & Solanum lycopersicum & - & France & 2010 & - & W \\
\hline 37 & $\underline{\text { GBBC } 1079}$ & $\mathrm{Cmm}$ & Solanum lycopersicum & - & France & 2010 & - & $\mathrm{P}$ \\
\hline 38 & GBBC 1080 & $\mathrm{Cmm}$ & Solanum lycopersicum & - & France & 2010 & - & $\mathrm{P}$ \\
\hline 39 & PD 5721 & $\mathrm{Cmm}$ & Solanum lycopersicum & - & France & 2006 & LMG 26819 & S \\
\hline 40 & PD 5719 & $\mathrm{Cmm}$ & Solanum lycopersicum & - & France & 2008 & - & K \\
\hline 41 & PD 5749 & $\mathrm{Cmm}$ & Solanum lycopersicum & Admiro & France & 2007 & GBBC $261=$ LMG 26628 & A \\
\hline 42 & PD 4545 & $\mathrm{Cmm}$ & Solanum lycopersicum & - & Germany & 2003 & LMG 26617 & D \\
\hline 43 & $\underline{\text { LMG } 7333^{\top}}$ & $\mathrm{Cmm}$ & Solanum lycopersicum & - & Hungary & 1957 & - & $\mathrm{R}$ \\
\hline 44 & PD 1386 & $\mathrm{Cmm}$ & Solanum lycopersicum & - & Italy & 1961 & NCPPB 1064 = LMG 3687 & K \\
\hline 45 & GBBC 242 & $\mathrm{Cmm}$ & Solanum lycopersicum & Daniëlla & Morocco & 2003 & PD 5750 = LMG 26629 & M \\
\hline 46 & LMG 5602 & $\mathrm{Cmm}$ & Cyphomandra betacea & - & New Zealand & 1967 & - & $x$ \\
\hline 47 & PD 5699 & $\mathrm{Cmm}$ & Solanum lycopersicum & - & Portugal & 1998 & - & N \\
\hline 48 & LMG 3695 & $\mathrm{Cmm}$ & Solanum lycopersicum & - & Romania & 1970 & - & F \\
\hline 49 & $\underline{\text { PD } 4149}$ & $\mathrm{Cmm}$ & Solanum lycopersicum & - & Slovenia & 2001 & LMG 26619 & B \\
\hline 50 & ES 2686.1 & $\mathrm{Cmm}$ & Solanum lycopersicum & - & Spain (Granada) & 2002 & - & J \\
\hline 51 & $\underline{\text { PD } 1664}$ & $\mathrm{Cmm}$ & Solanum lycopersicum & - & Sweden & - & LMG 26805 & $\mathrm{R}$ \\
\hline 52 & PD 5722 & $\mathrm{Cmm}$ & Solanum lycopersicum & - & Switzerland & 2007 & - & $\mathrm{T}$ \\
\hline 53 & PD 1948 & $\mathrm{Cmm}$ & Solanum lycopersicum (seeds) & - & Taiwan & 1988 & PD $1683=$ LMG 26625 & G \\
\hline 54 & $\underline{\text { GBBC } 247}$ & $\mathrm{Cmm}$ & Solanum lycopersicum & - & The Netherlands (Velden) & 2004 & - & $H$ \\
\hline 55 & LMG 3681 & $\mathrm{Cmm}$ & Solanum lycopersicum & - & United Kingdom & 1956 & NCPPB 382 & V \\
\hline 56 & PD 5751 & $\mathrm{Cmm}$ & Solanum lycopersicum & - & USA & 1998 & GBBC $172=$ LMG 26630 & $\mathrm{O}$ \\
\hline 57 & LMG 26807 & Clavibacter-like & Solanum lycopersicum (seeds) & - & India & 2000 & PD 5683 & na \\
\hline 58 & LMG 26810 & Clavibacter-like & Solanum lycopersicum (seeds) & - & Chile & 2007 & PD 5686 & na \\
\hline 59 & LMG $3663^{\top}$ & $\mathrm{Cmi}$ & Medicago sativa & - & USA & 1955 & NCPPB 1109 & na \\
\hline 60 & LMG $5627^{\top}$ & $\mathrm{Cmn}$ & Zea mays & - & USA & 1971 & NCPPB $2581=$ LMG $3700^{\top}$ & na \\
\hline 61 & LMG $7294^{\top}$ & $\mathrm{Cmt}$ & Triticum aestivum (Aestivum Group) & - & - & 1978 & ATCC 33566 & na \\
\hline 62 & LMG $2889^{\top}$ & Cms & Solanum tuberosum & - & Canada & 1968 & NCPPB 2137 & na \\
\hline
\end{tabular}

Bacterial collection abbreviations: LMG-BCCM/LMG-Bacterial Collection (Ghent, Belgium), PD-PD collection (Wageningen, The Netherlands) and GBBC-GBBC collection (ILVO, Merelbeke, Belgium).

*Nursery BPK, Duffel, Belgium, ${ }^{*}$ Instituto Canario de Investigaciones Agrarias (Tenerife, Spain), eight underlined strains were included in an initial testing of VNTR loci.

${ }^{2} \mathrm{Cmm}$-Clavibacter michiganensis subsp. michiganensis, Cmn-Clavibacter michiganensis subsp. nebraskensis, Cms-Clavibacter michiganensis subsp. sepedonicus, Cmi-Clavibacter michiganensis subsp. insidiosus, Cmt-Clavibacter

michiganensis subsp. tessellarius.

- Cultivar unknown; geographical origin unknown; year of isolation unknown; no alternative number.

${ }^{3}$ ng-new greenhouse, og-old greenhouse.

4 na-not applicable. 
Table 2 Primers sequences used in this study

$\mathrm{Nr} \quad$ Name $\quad$ Amplification primers (seq)

1 Clav-VNTR2 F-5'-GGTCTACGTCGACGAGGTCTT-3'

F- 5'-GCACCGCCACATGGAGAG-3'

R-5'-GTCGACGCGCTACGGGAG-3'

2 Clav-VNTR5 F-5'-GGGCCCGATCAACGACAT-3' F-5'-CGGACACGTCAGCCTACC-3' F-5'-CATCGAGTCGGCCCTGGT-3' F-5'-GAGATCGCCACGCAGCTC-3'

3 Clav-VNTR9 F-5'-GCACGGCGTCACGGTCAG-3' F-5'-CGAGGAGTGGAACCAGGCCG-3' F-5'-AGCTCGCGAAGCCGTCCAC-3' F-5'-CGAAGGCCTCCAAGGGCCAG-3'

4 Clav-VNTR13 F-5'-GTCGTGGTGCGGGGTCGT-3' F-5'-ACGTCCAGCATTCCTCCA-3' F-5'-TGACCGGCACGTCAAGGAGA-3' F-5'-ACGTCCAGCATTCCTCCA-3'

5 Clav-VNTR15 F-5'-GCCGTCTCTGCGTCTTTC-3' F-5'-CCTCGAGATGACACCTGAAT-3' F-5'-ATGAGACGTCCAGCAGTGG-3' F-5'-GATGTGTACGATCCGCTCTC-3'

6 Clav-VNTR16 F-5'-GTCGCCTACGAGTTCATGGT-3' F-5'-GTCACGGCGCCCTAGGAACC-3' F-5'-AGCTCCTCAACAGCCTCGT-3' F-5'-TCGGCCAGTGCAGCGTCA-3'

7 Clav-VNTR22 F-5'-ACACCCGCCCGACTAGACC-3' F-5'-GACAGGCCGGTCGGAGGAAT-3' F-5'-CGGAAGCTGCACGACGAC-3' F-5'-GTGCGCGGCGTCGGATAC-3'

8 Clav-VNTR26 F-5'-CCTTCGCGGTGCGGATCA-3' F-5'-GACGAGGACGGTGTCGAG-3' F-5'-GGGATCGTCGACGGCATGAG-3' F-5'-GCTGGTGATCGTCTCCAACT-3'

9 gyrB $2 F$ F-5'-ACCGTCGAGTTCGACTACGA-3' The same as amplification primers gyrB $4 R \quad$ F-5'- CCTCGGTGTTGCCSARCTT-3'

10 dnAA F-TACGGCTTCGACACCTTCG-3 dnaA $R$ 5-CGGTGATCTTCTTGTTGGCG-3

Position in a genome

3107999-3108175

put

putative

Gene (ORF)

(putive zinc-dependant oxidoreductase carboxylesterase)
(putions

putative transcriptional regulator (MerR family)

$2183702-2183742$

putative arylesterase (putative transcriptional regulator, LysR-family)

$468356-468428$

putative NAD(FAD)-dependent dehydrogenase

$200-250$

$2684839-2684928$

putative duplicated acetyltransferase

$130-200$

1929615-1929835

putative glycine/betaine $\mathrm{ABC}$ transporter

(Putative DNA or RNA helicase)

549526-549594

putative two-component system response regulator

$175-300$

$175-225$

$178774-178838$

putative urea amidolyase (conserved hypothetical protein)

6588-7113

DNA gyrase, subunit B

150-175

525

412-1345

agenome of Cmm NCPPB 382 (AM711867). 
amplicons were $675 \mathrm{bp}$ and $440 \mathrm{bp}$ long (equal length was used for all strains), respectively. A phylogenetic tree was constructed on $d n a A$-gyrB concatenated sequence data with Molecular Evolutionary Genetics Analysis software (Mega 5.1) [41], using the Maximum Likelihood method with the Tamura-Nei model [42] and 1000 bootstrap replicates. The position of the sequenced $g y r B$ and $d n a A$ amplicons were checked by comparison to the reference Cmm genome sequence (AM711867). Newly generated $\operatorname{gyr} B$ and $d n a A$ sequences have following accession numbers KC521547-521623 and have been deposited in NCBI database. Each unique sequence of a gene was assigned an allele number and the combination of allele numbers for each isolate defined the haplotype. Number of haplotypes, haplotype diversity and number of polymorphic sites were estimated for $\operatorname{gyr} B$ and $d n a A$ genes using DnaSP version 5.0 [43]. Percentages of polymorphic sites at the analyzed loci were calculated by dividing the number of polymorphic positions by the total length of the gene. The Discriminatory Power (D) was calculated using a discriminatory power calculator (http://insilico. ehu.es/mini_tools/discriminatory_power/index.php). The Discriminatory Power (D), as shown by Hunter can be expressed by the formula of Simpson's index of diversity, which reads:

$$
D=1-\frac{1}{N(N-1)} \sum_{j=1}^{s} x_{j}\left(x_{j}-1\right)
$$

Where $\mathrm{D}$ is the index of discriminatory power, $\mathrm{N}$ the number of unrelated strains tested, $\mathrm{S}$ the number of different types, and $x j$ the number of strains belonging to the jth type, assuming that strains will be classified into mutually exclusive categories. Thus, a D value of 1.0 would indicate that a typing method was able to distinguish each member of a strain population from all other members of that population. Conversely, an index of 0.0 would indicate that all members of a strain population were of an identical type. An index of 0.50 would mean that if one strain was chosen at random from a strain population, then there would be a $50 \%$ probability that the next strain chosen at random would be indistinguishable from the first [44].

\section{Design of VNTR primers}

The complete genome sequence of Clavibacter michiganensis subsp. michiganensis NCPPB 382 deposited under accession number AM711867 was screened for VNTR loci. Tandem Repeat Finder program (http://tandem.bu.edu) [45] was used to detect potential VNTR loci. Primer3 software [46] was used to design locus-specific amplifications and sequencing primers in regions flanking VNTR loci. Eight loci (Table 3) of $20 \mathrm{bp}$ to $45 \mathrm{bp}$ long tandem repeat (TR) units were selected. TRs longer than $20 \mathrm{bp}$ were chosen to enable easier interpretation of results from an agarose gel. Primer pairs targeting single locus alleles were manually designed in the conserved regions to obtain amplicons of no more than $450 \mathrm{bp}$ in length.

\section{VNTR PCR amplification and sequencing}

The PCR mixture had a total volume of $25 \mu \mathrm{l}$, containing 1 x PCR buffer (100 mM Tris- $\mathrm{HCl}, 15 \mathrm{mM} \mathrm{MgCl}_{2}$, $500 \mathrm{mM} \mathrm{KCl}[\mathrm{pH} \mathrm{8.3]}$ ) (Qiagen), dNTP's $0.2 \mathrm{mM}$ each, $0.6 \mu \mathrm{M}$ of each primer, $0.5 \mathrm{U}$ DNA Taq polymerase, and 50-60 ng template DNA. The PCR amplifications were performed under following conditions: 3 min denaturation step at $94^{\circ} \mathrm{C} ; 35$ cycles of $94^{\circ} \mathrm{C}$ for $1 \mathrm{~min}$, annealing at $60^{\circ} \mathrm{C}$ for $1 \mathrm{~min}$, and extention at $72^{\circ} \mathrm{C}$ for $1 \mathrm{~min}$; and a final extension step at $72^{\circ} \mathrm{C}$ for $10 \mathrm{~min}$. Amplified products were run on a $2.5 \%$ Gel Pilot ${ }^{\circ}$ Small Fragment Agarose (Qiagen) at $110 \mathrm{~V}$ for $2.5 \mathrm{hrs}$ at $4^{\circ} \mathrm{C}$ using $25 \mathrm{bp}$ size marker (Invitrogen), and visualized by ethidium bromide staining. PCR amplicons from one representative strain per different locus of a particular VNTR were sequenced using sequencing primers (Table 2 ) according to the sequencing protocol described above for $g y r B$ and $d n a A$ genes.

\section{VNTR analysis and statistics}

Product sizes were estimated and the exact number of repeats present was calculated using a derived allelenaming table, based on the number of repeats which could theoretically be present in a PCR product of a given size, allowing for extra flanking nucleotides and primer size. Theoretical number of repeats was confirmed subsequently by sequencing. Loci were named simply on the basis of the order in which they were found by the initial search. VNTR allele calls were analyzed in BioNumerics as 'character' data. Composite datasets were created for the eight Clav-VNTR loci. Distance trees were derived by clustering with the unweighted pair group method with arithmetic means (UPGMA), using 'categorical' character table values. All markers were given equal weight, irrespective of the number of repeats. The percentages in the dendrogram reflect the percentage of homology between the specific markers. Relatedness between the different haplotypes was investigated based on comparison of allelic profiles using the minimum spanning tree (MST) method from BioNumerics v 5.1. We used the classical criterium of one allelic mismatch to group haplotypes into clonal complexes. In order to assess the evolutionary relatedness between haplotypes the MLVA data was analyzed taking into account the number of repeat differences. The type strain LMG $7333^{\mathrm{T}}$ served as a reference and a starting point for calculations of the differences in other strains. For each VNTR locus the Hunter-Gaston and Simpson's diversity indices were calculated using the VNTR diversity and confidence extractor software (V-DICE) available at the Health 
Table 3 Range of repeats, size of repeats, numbers of alleles and diversity indices (Simpson's, Hunter-Gaston and Shannon-Wiener) for each VNTR locus used to investigate 56 Clavibacter michiganensis subsp. michiganensis strains

\begin{tabular}{lcccccc}
\hline Locus & $\begin{array}{c}\text { Range of } \\
\text { repeats }\end{array}$ & $\begin{array}{c}\text { Size of repeat } \\
(\mathbf{b p})\end{array}$ & Nr of alleles & $\begin{array}{c}\text { Simpson's } \\
\text { diversity index }{ }^{\mathbf{a}}\end{array}$ & $\begin{array}{c}\text { Hunter-Gaston } \\
\text { diversity index }^{\mathbf{a}}\end{array}$ & $\begin{array}{c}\text { Shannon-Wiener } \\
\text { index of diversity }^{\mathbf{b}}\end{array}$ \\
\hline Cmm-V5 & $3-8.5$ & 46 & 6 & 0.652 & 0.664 & 1.3377 \\
Cmm-V9 & $1-3$ & 20 & 3 & 0.577 & 0.588 & 0.932 \\
Cmm-V13 & $1-3$ & 35 & 3 & 0.534 & 0.544 & 0.8225 \\
Cmm-V2 & $2-5$ & 45 & 3 & 0.53 & 0.54 & 0.844 \\
Cmm-V26 & $1-2$ & 33 & 3 & 0.494 & 0.503 & 0.677 \\
Cmm-V15 & $3-5$ & 34 & 5 & 0.417 & 0.425 & 0.7334 \\
Cmm-V16 & $2-6.5$ & 47 & 2 & 0.392 & 0.399 & 0.8864 \\
Cmm-V22 & $1-3$ & 26 & 0.504 & 0.514 & 0.5811 \\
\hline
\end{tabular}

Diversity Index (for VNTR data) = A measure of the variation of the number of repeats at each locus. Ranges from 0.0 (no diversity) to 1.0 (complete diversity) ${ }^{a}$ Calculated by V-DICE (http://www.hpa-bioinformatics.org.uk/cgi-bin/DICI/DICl.pl).

${ }^{\mathrm{b}}$ Calculated in BioNumerics v 5.1.

Protection Agency bioinformatics tools website (http:// www.hpa-bioinformatics.org.uk/cgi-bin/DICI/DICI.pl) [47]. Shannon-Wiener index of diversity was calculated using BioNumerics version 5.1.

\section{Results}

Assessment of genetic diversity among Clavibacter strains In total, 62 strains representing the Clavibacter subspecies and non-pathogenic Clavibacter-like strains were included in this study. The identity of included $\mathrm{Cmm}$ strains was confirmed by analysis of the $\operatorname{gyr} B$ and $d n a A$ gene sequences. The gene sequence analyses were performed on several related Clavibacter strains in order to study the genetic diversity in the genus Clavibacter. Phylogenetic analysis of two tested genes confirmed a clear separation of Clavibacter subspecies and a distinct position of non-pathogenic Clavibacter-like strains. Phylogenetic relationship between the Clavibacter subspecies and nonpathogenic Clavibacter-like strains was strongly supported by high bootstrap values (Figure 1). The number of polymorphic sites was $47(10.7 \%)$ and $87(12.9 \%)$, for gyrB and $d n a A$, respectively. It has to be noted that diversity among Cmm strains, especially among strains from recent Belgian outbreaks, was small which resulted in a limited number of clusters. Despite a low genetic diversity, a number of groups could be distinguished in a $\mathrm{Cmm}$ cluster (Figure 1). The largest cluster, containing Belgian strains from recent outbreaks and two French strains from 2010 (GBBC 1077 and GBBC 1078), was separated from the $\mathrm{Cmm}$ strains isolated previously in Belgium (Figure 1). Furthermore, strains originating from the same location mostly grouped together, such as French strains GBBC 1079, GBBC 1080 and PD 5719. However, based on the concatenated Maximum Likelihood tree of $g y r B$ and $d n a A$ no clear geographical separation among $\mathrm{Cmm}$ strains could be demonstrated. In $g y r B$ and $d n a A$ trees (data not shown) and in a concatenated tree Clavibacter subspecies are separated from each other and from non-pathogenic strains which suggests that they present the same phylogenetic information (Figure 1).

\section{Development and implementation of MLVA}

In parallel with the sequence analysis $\mathrm{Cmm}$ strains were investigated with MLVA. Fifty eight VNTR loci were identified in the genome of Cmm NCPPB 382. Thirty one of them were tested on a set of eight genetically diverse Cmm strains originating from geographically spread locations (Table 1). Subsequently, eight loci that were successfully amplified and showed to be polymorphic in the tested subset of strains were selected for further analysis. Successful amplification was obtained in all tested Cmm strains. Regarding the non-pathogenic, seed-borne Clavibacter-like strains the results varied from no amplification for Clav-VNTR5 or unspecific (more than one band, not expected product size) bands in Clav-VNTR26 (data not shown). Similar findings were observed for Clavibacter subspecies other than $\mathrm{Cmm}$. In the cluster analysis, a total of 24 MLVA types were detected among $56 \mathrm{Cmm}$ strains when the data from eight loci were combined, with allele numbers per locus ranging from two (Clav-VNTR22, Clav-VNTR26) to six (Clav-VNTR5) (Table 3, Figure 2). A large cluster, comprised of $\mathrm{Cmm}$ strains from recent Belgian outbreaks together with two French strains isolated in 2010, exhibited identical MLVA haplotypes. Strains from other countries formed mostly a separate branch or a cluster with two strains with an identical MLVA haplotype. No direct connection between strains from recent Belgian outbreaks of 2010-2012 and other Belgian strains included in this study could be observed. Remarkably, Belgian strains PD 5736 and GBBC 285, isolated in 1983 and 2008, respectively, showed the same MLVA haplotypes. In the concatenated tree of gyrB and $\operatorname{dnaA}$ these two Belgian strains clustered together among strains originating from other countries (Figure 1). 


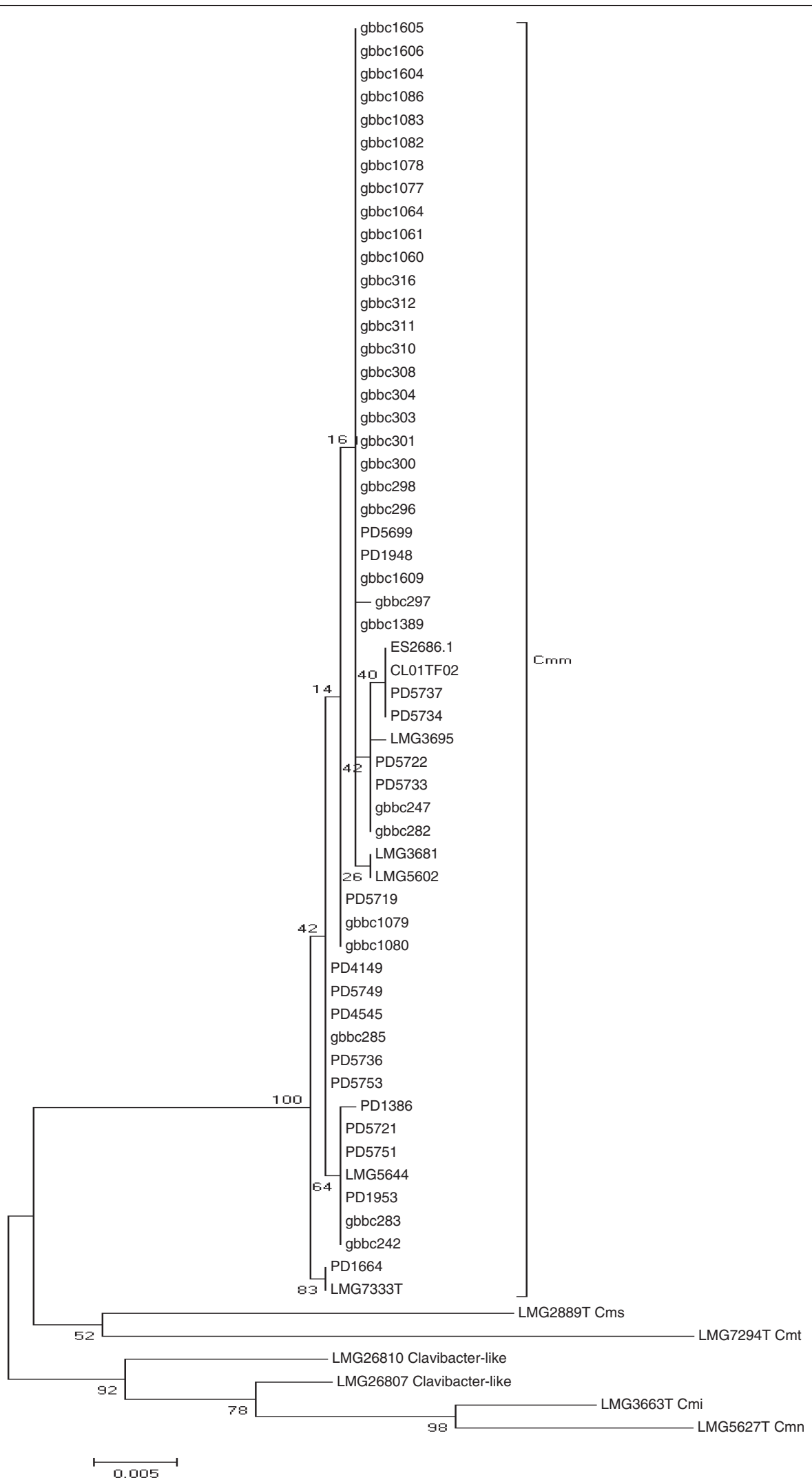

Figure 1 Phylogenetic analysis of concatenated tree of $d n a A$ and gyrB sequences based on 1115 bp. Maximum Likelihood (ML) tree with the Tamura-Nei model of 62 Clavibacter strains with bootstrap values generated from 1000 replicates. 
Similar findings were observed for other two Belgian strains PD 1953 and GBBC 283, isolated in 1984 and 2002, respectively.

The discriminatory abilities of the MLVA technique was determined by calculating the discriminatory index (D) for 56 typed strains. MLVA differentiated $25 \mathrm{Cmm}$ strains and showed a level of discrimination, with a $D$ value of 0.8006 . The discriminatory power of each VNTR was estimated by the number of alleles detected and the allele diversity. The number of different alleles ranged from two for $\mathrm{Cmm}-\mathrm{V} 22$ and $\mathrm{Cmm}-\mathrm{V} 26$ to six for Cmm-V5. Highest allelic diversities measured by Hunter-Gaston, Simpson's and Shannon-Wiener diversity indices were $0.664 ; 0.652 ; 1.3377$, respectively and were observed for the loci Clav-VNTR5 (Table 3). For the set under study, 27 different alleles of eight VNTR loci were observed. The relationship among the strains based on MLVA results is presented in a minimum 
spanning tree (MST) (Figure 3). The $56 \mathrm{Cmm}$ strains were resolved into 24 types distributed into five complexes separating double locus variants (DLV). In addition, a large clonal group of Belgian strains from recent outbreaks (W), six singletons (S, T, Q, X, V, U) each represented by an isolate from a different country, and one separate group consisting of two strains (R) were detected (Table 1, Figure 3). Based on MLVA results, strains from Belgian outbreaks 2010-2012 were identical; no differences could be observed between strains originating from different years of isolation, tomato varieties or geographic locations in Belgium (Table 1, Figure 2, and Figure 3). To receive more information about evolutionary relatedness of strains from Belgium and France the MLVA data was analyzed taking into account the number of repeat differences (Additional file 1: Figure S1). Interestingly, Belgian strain PD 5737 and French strain PD 5749 clustered closer to ES2686.1 and CL01TF02 strains isolated in Spain during bacterial canker outbreak in 2002-2003. Moreover, these four strains showed to have a more similar MLVA haplotype to the group of strains from recent Belgian outbreaks 2010-2012.

\section{Discussion and conclusion}

Over the last few decades, bacterial canker has been frequently detected in tomato production areas, leading to substantial financial and economical losses. Only during the last three years several local outbreaks of $\mathrm{Cmm}$ were reported in Belgium. In some cases, reoccurring infections were detected in the primarily contaminated farms, suggesting a persistence of an initial infection source. Despite a quite frequent detection of tomato canker and wilting in Belgian tomato production areas there is little known about the genetic diversity of $\mathrm{Cmm}$ strains which hinders the correct conclusions about the probable sources of epidemics and transmission routes of Cmm.

This study is the first MLVA approach developed for efficient genotyping of $\mathrm{Cmm}$ strains. To date typing of

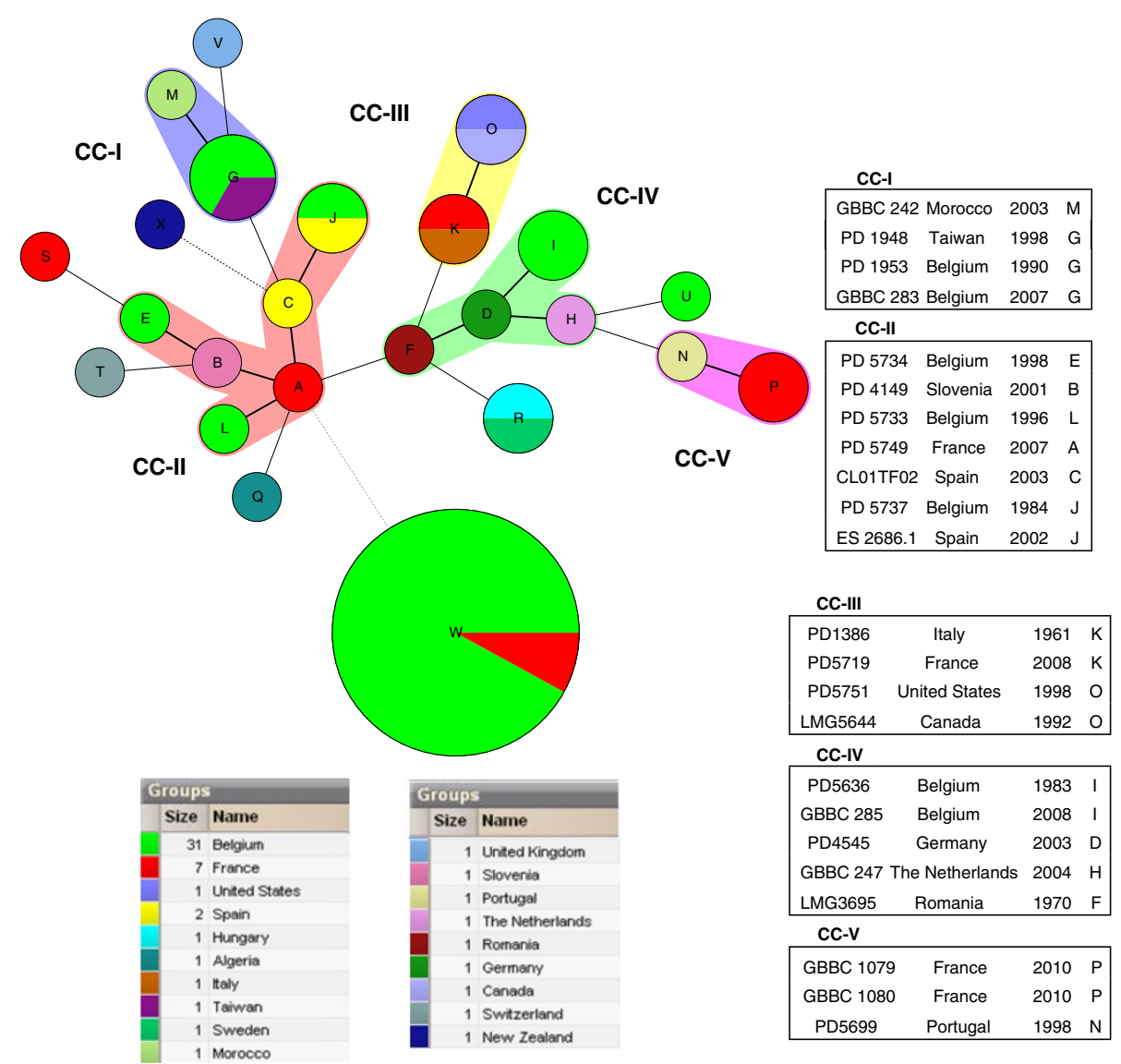

Figure 3 Minimum spanning tree of $56 \mathrm{Cmm}$ strains based on eight VNTR loci. Each circle represents an MLVA type with a size corresponding to the number of strains that share an identical MLVA type. MLVA types connected by a thick solid line differ from one another by one VNTR locus, while MLVA types connected by a thin solid line differ by two VNTR loci. MLVA types that differ from each other by three, four or more VNTR loci are connected by dashed and dotted lines. MLVA types were distinguished to define clonal complexes and to group in zones MLVA types that differ from one another by at most two locus variants. Letters visible on each circle are corresponding to strains described in Table 1. CC-Clonal complex. 
Cmm strains was performed by RAPD-PCR [6], BOX-PCR [8,48], AFLP [6], PFGE [10] and MLST [7]. Despite the fact that some of these methods were found to have a good resolution most of them have limitations such as a poor interlaboratory portability or limited exchangeability of results that were generated on a specific machine or compared to an in-house database. Nowadays, fully sequenced genomes give a unique opportunity for a development of more robust and accurate typing methods such as MLVA. Its advantages, such as, high reproducibility, exchangeability of results and the possibility to add loci greatly facilitates epidemiological studies of economically important pathogens such as $\mathrm{Cmm}$.

In this work, Clav-VNTR5 showed to be the most polymorphic loci with five different alleles and the highest HGDI of 0.664. Combined data from MLVA analysis of all eight investigated loci resulted in 25 different haplotypes and a discriminatory power of 0.8006 . Cmm strains from the recent epidemics in Belgium in 2010-2012 showed identical MLVA haplotypes which suggests that a clonal population was responsible for these outbreaks. The presence of the same MLVA haplotypes of Cmm strains from 2011 and 2012 could mean that bacteria persisted in the used equipment, devices or soil and induced the outbreaks in the following years. Population of Belgian strains isolated from $2010-2011$ is epidemiologically related to at least two French strains that exhibited the same MLVA haplotype. Moreover, based on minimum spanning tree, Belgian strains were found to be evolutionary related to the French strain PD 5749. When MLVA data was analyzed taking into account differences in the number of repeats it appeared that two French and two Spanish strains were found to have a similar MLVA haplotype to the group of Belgian strains from 2010-2012 suggesting that there might be a common origin of these strains (Additional file 1: Figure S1). It is worth mentioning that the strain ES 2686.1 isolated in Spain in 2002 was linked to outbreaks of Cmm in 2002-2007 in Canary Islands [6]. Two French strains isolated in 2010 showed the same MLVA haplotype as strains from recent Belgian outbreaks which may imply that the contaminated material was spread also in France. Different MLVA patterns between strains from the recent Belgian outbreaks of 2010-2012 and Belgian strains isolated previously support our hypothesis about a novel introduction, presumably originating from a single lot of seeds or contaminated tomato seedlings. Remarkably, all Belgian Cmm strains from 2010-2012 (Table 1), were purchased from the same nursery.

In this study, VNTR loci were chosen to be longer than or equal to $20 \mathrm{bp}$ to simplify the interpretation of the results from an agarose gel and to allow performing the analysis in standard laboratories not equipped in sophisticated tools (fragment analyzer or sequencer) required to analyze small (a few nucleotides) differences in an amplicon size. Shorter repeats are represented in a higher number of copies and are more likely to be polymorphic [49]. However, many studies showed successful application of longer repeats which gave satisfactory resolution and discriminatory power $[16,50]$. Moreover, in silico analysis of tandem repeats in the Cmm genome NCPPB 382 revealed only a few short repeats $(6-8 \mathrm{bp})$ that had remarkably higher number of copies (around 10 copies). These microsatellite loci might be investigated in the future and combined with currently available MLVA scheme. MLVA can provide phylogenetic information even with a limited number of loci [51]. MLVA assays are relatively robust $[17,52]$ but as any other technique they have their limitations. In MLVA, a need to develop a new set of loci for every species or serovar under investigation might be necessary. Moreover, some loci are 'not stable' and can 'disappear' from some strains or lineages what will result in an uninformative 'zero' allele [53].

VNTRs might possibly contribute to the genomic polymorphism and/or evolution. Comparative genomics of pathogenic Mycobacterium tuberculosis showed that a variation in size and number of repeats, located in coding regions, can result in a variable expression of surfaceexposed proteins that play a role in pathogenicity [54]. These changes could possibly help the pathogen to avoid the host immune response. Expansion or reduction of the number of tandem repeats can influence the expression, structure and activity of cellular proteins. Tandem repeats located within regulatory regions can result in a modification of gene expression at the transcriptional level [55]. All tested Clav-VNTR loci were found in putative coding

Table 4 Discrimination indices for Clavibacter typing methods

\begin{tabular}{|c|c|c|c|c|c|}
\hline Typing technique & $\begin{array}{l}\text { Hunter-Gaston } \\
\text { diversity index }\end{array}$ & $\begin{array}{c}\text { Number of } \\
\text { haplotypes }\end{array}$ & $\begin{array}{c}\text { Number of } \\
\text { polymorphic sites }\end{array}$ & Number of sites & $\%$ of polymorphic sites \\
\hline gyrB & $0.586^{b}$ & 10 & 47 & 440 & 10.7 \\
\hline$d n a A$ & $0.662^{b}$ & 12 & 87 & 675 & 12.9 \\
\hline Concatenated gyrB-dnaA & $0.758^{b}$ & 17 & 134 & 1115 & 12.0 \\
\hline MLVA & $0.800^{\mathrm{a}}$ & 25 & na & na & na \\
\hline
\end{tabular}

${ }^{a}$ Calculated in discriminatory Power Calculator (http://insilico.ehu.es/mini_tools/discriminatory_power/) based on $56 \mathrm{Cmm}$ strains.

${ }^{\mathrm{b}}$ Calculated in DnaSP v.5 [44] based on $56 \mathrm{Cmm}$ strains.

na- not applicable. 
regions (Table 2). At least two of them were found within genes linked to processes taking place in a cell envelope (Clav-VNTR-13: putative NAD (FAD)-dependent dehydrogenase and Clav-VNTR 16: putative glycine/ betaine $\mathrm{ABC}$ transporter). We could speculate that variability observed within these regions might possibly help bacteria to alternate the proteins of a cell envelope. However, more research has to be performed on the role of tandem repeat copy, and virulence in $\mathrm{Cmm}$.

The genetic structure of the studied strains was assessed by the sequence analysis of two housekeeping genes, $\operatorname{gyr} B$ and $d n a A$, which were previously reported to be good molecular markers for studying populations of the genus Clavibacter [32,38]. The phylogenetic position of $\mathrm{Cmm}$ strains was supported by high bootstrap values in a Maximum Likelihood tree. High similarity of Belgian strains from recent outbreaks was detected both, in a gene sequence analysis and by an MLVA typing method, supporting the hypothesis about their monomorphic nature. The percentages of polymorphic sites observed for the concatenated set of $g y r B$ and $d n a A$ genes (Table 4) was higher than the value obtained from five concatenated genes described in a recently published MLSA scheme of Clavibacter michiganensis subsp. michiganensis, (12 versus 8.8) [33]. Based on these parameters the genes selected in this work can be applied in MLST studies to investigate highly similar Cmm populations.

In this study, MLVA was successfully applied to investigate a genetic relationship of $\mathrm{Cmm}$ strains from recent Belgian outbreaks. Its discriminatory power, measured by HGDI, was higher than these of each of the tested genes, gyrB and dnaA (Table 4). Our study has shown that MLVA analysis offers better discrimination of $\mathrm{Cmm}$ strains $(\mathrm{HGDI}=0.8)$ than the typing method based on the concatenated tree of $\operatorname{gyr} B$ and $d n a A$ (HGDI $=0.758)$ (Table 4). A significant advantage of the MLVA method is the excellent interlaboratory reproducibility [56] which makes this method well-suited for accurate and reproducible bacterial typing applicable in epidemiological studies of Clavibacter. MLVA, with its high discriminatory power to separate closely related strains, might be very useful for tracking sources of epidemic outbreaks as well as for investigating various haplotypes occurring during these outbreaks, as illustrated in the differentiation of $\mathrm{Cmm}$ strains. The technique is fast (results within one day), easy to perform, user-friendly, cost-effective compared to other typing techniques (e.g. AFLP) with an excellent reproducibility (intra- and interlaboratory). Additionally, data storage, comparison and exchange of the results are possible and easy. Moreover, the use of fluorescencelabeled primers enables multiplex PCR and subsequent analysis in a fragment analyzer. It is worth mentioning that the MLVA scheme, derived from in silico analysis of a complete genome sequence of $\mathrm{Cmm}$, was experimentally confirmed to be accurate. It is consistent with previous findings demonstrated for Xanthomonas citri pv. citri and is advantageous over other experimentally tested techniques such as AFLP or IS-LM-PCR, where in vitro vs. in silico accuracy values of $75 \%$ and $87 \%$, respectively, were reported [31].

The MLVA method, with eight novel VNTR loci identified within the genome of $\mathrm{Cmm}$, demonstrated its applicability as a new tool for the molecular investigation of bacterial wilting and canker outbreaks.

In the future, additional VNTR loci and Clavibacter isolates might enable unraveling intrapopulation genetic variation and assessing the robustness of the method for investigating bacterial canker outbreaks on a global scale.

\section{Additional file}

Additional file 1: Figure S1. Grouping of $56 \mathrm{Cmm}$ strains using categorical values and the UPGMA (Unweighted-Pair Group Method with Arithmetic Mean) algorithm, generated with BioNumerics 5.1 software based on the number of repeats differences. Numbers in the Cmm-V2-26 columns indicate numbers of repeats differences.

\section{Competing interests}

The other authors declare that they have no competing interests.

\section{Authors' contributions}

PS, MM, JW and PDV conceived the study and participated in its design and coordination. JW and PDV provided the bacterial culture collection for the study. JZ participated in the design of the study, carried out the molecular work, performed the data analysis and drafted the manuscript. PS coordinated the work and performed the statistical analysis. All authors read and approved the final manuscript.

\section{Acknowledgements}

We thank the PD, GBBC and BCCM/LMG collections and Ana Rodríguez Pérez (Spain) for providing necessary strains. This work was performed in the Seventh Framework Programme of project KBBE-2008-1-4-01 (QBOL) nr 226482 funded by the European Commission. Het Fonds Wetenschappelijk Onderzoek-Vlaanderen (FWO) is acknowledged for the postdoctoral fellowship of Pieter Stragier, and the Belgian NPPO (FAW) for partially financing ILVO-research. We thank dr. Kim Heylen for her critical reading and valuable comments on the manuscript.

\section{Author details}

${ }^{1}$ Laboratory of Microbiology, Department of Biochemistry and Microbiology, Ghent University, K.L. Ledeganckstraat 35, B-9000 Gent, Belgium. ²Plant-Crop Protection, Institute for Agricultural and Fisheries Research, ILVO, Burg. Van Gansberghelaan 96, B-9820 Merelbeke, Belgium. ${ }^{3}$ BCCM/LMG Bacteria collection - Laboratory of Microbiology Department of Biochemistry and Microbiology, Ghent University, K.L. Ledeganckstraat 35, B-9000 Gent, Belgium.

Received: 18 February 2013 Accepted: 24 May 2013 Published: 5 June 2013

\section{References}

1. De León L, Siverio F, Lopez MM, Rodriguez A: Clavibacter michiganensis subsp. michiganensis, a seedborne tomato pathogen: healthy seeds are still the goal. Plant Dis 2011, 95(11):1328-1338.

2. EPPO: Clavibacter michiganensis subsp. michiganensis Diagnostics, $\mathrm{PM7/42.}$ Bulletin OEPP/EPPO 2005, 35:273-283.

3. Strider DL: Bacterial canker of tomato caused by Corynebacterium michiganense: a literature review and bibliography. Technical Bulletin North Carolina Agricultural Experiment Station; 1969:193. 
4. Jahr H, Bahro R, Burger A, Ahlemeyer J, Eichenlaub R: Interactions between Clavibacter michiganensis and its host plants. Environ Microbiol 1999, 1(2):113-118.

5. Lamichhane JR, Balestra GM, Varvaro L: Severe Outbreak of Bacterial Canker Caused by Clavibacter michiganensis subsp. michiganensis on Tomato in Central Italy. Plant Dis 2011, 95(2):221-221.

6. De León L, Rodriguez A, Llop P, Lopez MM, Siverio F: Comparative study of genetic diversity of Clavibacter michiganensis subsp. michiganensis isolates from the Canary Islands by RAPD-PCR, BOX-PCR and AFLP. Plant Pathol 2009, 58(5):862-871.

7. Milijašević-Marčić S, Gartemann KH, Frohwitter J, Eichenlaub R, Todorović B, Rekanović E, Potočnik I: Characterization of Clavibacter michiganensis subsp. michiganensis strains from recent outbreaks of bacterial wilt and canker in Serbia. Eur J Plant Pathol 2012, 134:697-711.

8. Kawaguchi A, Tanina K, Inoue K: Molecular typing and spread of Clavibacter michiganensis subsp. michiganensis in greenhouses in Japan. Plant Pathol 2010, 59(1):76-83.

9. Bella P, lalacci G, Licciardello G, La Rosa R, Catara V: Characterization of atypical Clavibacter michiganensis subsp. michiganensis populations in greenhouse tomatoes in Italy. J Plant Pathol 2012, 94(3):635-642.

10. Kleitman F, Barash I, Burger A, Iraki N, Falah Y, Sessa G, Weinthal D, Chalupowicz L, Gartemann K, Eichenlaub R: Characterization of a Clavibacter michiganensis subsp. michiganensis population in Israel. Eur J Plant Pathol 2008, 121(4):463-475.

11. Sahin F, Uslu H, Kotan R, Donmez M: Bacterial canker, caused by Clavibacter michiganensis subsp. michiganensis, on tomatoes in eastern Anatolia region of Turkey. Plant Pathol 2002, 51(3):399-399.

12. Cangelosi GA, Freeman RJ, Lewis KN, Livingston-Rosanoff D, Shah KS, Milan SJ, Goldberg SV: Evaluation of a high-throughput repetitivesequence-based PCR system for DNA fingerprinting of Mycobacterium tuberculosis and Mycobacterium avium complex strains. $J$ Clin Microbiol 2004, 42(6):2685-2693.

13. Bosch T, de Neeling A, Schouls L, Zwaluw K, Kluytmans J, Grundmann H, Huijsdens X: PFGE diversity within the methicillin-resistant Staphylococcus aureus clonal lineage ST398. BMC Microbiol 2010, 10(1):40.

14. Van Belkum A: Tracing isolates of bacterial species by multilocus variable number of tandem repeat analysis (MLVA). FEMS Immunol Med Microbiol 2006, 49(1):22-27.

15. Van Belkum A, Scherer S, Van Alphen L, Verbrugh H: Short-sequence DNA repeats in prokaryotic genomes. Microbiol Mol Biol Rev 1998, 62(2):275

16. Harth-Chu E, Espejo RT, Christen R, Guzman CA, Hofle MG: Multiple-locus variable-number tandem-repeat analysis for clonal identification of Vibrio parahaemolyticus isolates by using capillary electrophoresis. Appl Environ Microbiol 2009, 75(12):4079-4088.

17. Lindstedt BA, Heir E, Gjernes E, Vardund T, Kapperud G: DNA fingerprinting of Shiga-toxin producing Escherichia coli 0157 based on multiple-locus variable-number tandem-repeats analysis (MLVA). Ann Clin Microbiol Antimicrob 2003, 2(1):12.

18. Danin-Poleg Y, Cohen LA, Gancz H, Broza YY, Goldshmidt H, Malul E, Valinsky L, Lerner L, Broza M, Kashi Y: Vibrio cholerae strain typing and phylogeny study based on simple sequence repeats. J Clin Microbiol 2007, 45(3):736-746.

19. Heymans R, Schouls LM, van der Heide HG: Schim van der Loeff MF, Bruisten SM: Multiple-locus variable-number tandem repeat analysis of Neisseria gonorrhoeae. J Clin Microbiol 2011, 49(1):354-363.

20. van Cuyck H, Pichon B, Leroy P, Granger-Farbos A, Underwood A, Soullie B, Koeck J-L: Multiple-locus variable-number tandem-repeat analysis of Streptococcus pneumoniae and comparison with multiple loci sequence typing. BMC Microbiol 2012, 12(1):241.

21. Skuce RA, McCorry TP, McCarroll JF, Roring SMM, Scott AN, Brittain D, Hughes SL, Hewinson RG, Neill SD: Discrimination of Mycobacterium tuberculosis complex bacteria using novel VNTR-PCR targets. Microbiology 2002, 148(2):519-528.

22. Marsh JW, O'Leary MM, Shutt KA, Pasculle AW, Johnson S, Gerding DN Muto CA, Harrison LH: Multilocus variable-number tandem-repeat analysis for investigation of Clostridium difficile transmission in hospitals. J Clin Microbiol 2006, 44(7):2558-2566.

23. Hidalgo Ă, Carvajal A, La T, Naharro G, Rubio P, Phillips ND, Hampson DJ: Multiple-locus variable-number tandem-repeat analysis of the swine dysentery pathogen, Brachyspira hyodysenteriae. J Clin Microbiol 2010, 48(8):2859-2865.
24. Le Fleche $P$, Hauck $Y$, Onteniente L, Prieur A, Denoeud F, Ramisse V, Sylvestre $P$, Benson $G$, Ramisse $F$, Vergnaud $G$ : A tandem repeats database for bacterial genomes: application to the genotyping of Yersinia pestis and Bacillus anthracis. BMC Microbiol 2001, 1(1):2.

25. Li Y, Cui Y, Hauck Y, Platonov ME, Dai E, Song Y, Guo Z, Pourcel C, Dentovskaya SV, Anisimov AP: Genotyping and phylogenetic analysis of Yersinia pestis by MLVA: insights into the worldwide expansion of Central Asia plague foci. PLoS One 2009, 4(6):e6000.

26. Zhao WJ, Chen HY, Zhu SF, Xia MX, Tan TW: One-step detection of Clavibacter michiganensis subsp. michiganensis in symptomless tomato seeds using a Taqman probe. J Plant Pathol 2007, 89(3):349-351.

27. Gironde S, Manceau C: Housekeeping Gene Sequencing and Multilocus Variable-Number Tandem-Repeat Analysis To Identify Subpopulations within Pseudomonas syringae pv. maculicola and Pseudomonas syringae pv. tomato That Correlate with Host Specificity. Appl Environ Microbiol 2012, 78(9):3266-3279

28. Coletta-Filho HD, Takita MA, De Souza AA, Aguilar-Vildoso Cl, Machado MA Differentiation of strains of Xylella fastidiosa by a variable number of tandem repeat analysis. App/ Environ Microbio/ 2001, 67(9):4091-4095.

29. Wang DY, Hadj-Henni L, Thierry S, Arna P, Chermette R, Botterel F, Hadrich I, Makni F, Ayadi A, Ranque S: Simple and Highly Discriminatory VNTR-Based Multiplex PCR for Tracing Sources of Aspergillus flavus Isolates. PLoS One 2012, 7(9):e44204.

30. Bergsma-Vlami M, Martin W, Koenraadt H, Teunissen H, Pothier J, Duffy B, van Doorn J: Molecular typing of Dutch isolates of Xanthomonas arboricola pv. pruni isolated from ornamental cherry laurel. J Plant Pathol 2012, 94(1):S1. 29-S21. 35.

31. Bui Thi Ngoc L, Vernire C, Jarne P, Brisse S, Guerin F, Boutry S, Gagnevin L, Pruvost O: From local surveys to global surveillance: three high-throughput genotyping methods for epidemiological monitoring of Xanthomonas citri pv. citri pathotypes. Appl Environ Microbiol 2009, 75(4):1173-1184.

32. Zaluga J, Heylen K, Van Hoorde K, Hoste B, Van Vaerenbergh J, Maes M, De Vos P: GyrB sequence analysis and MALDI-TOF MS as identification tools for plant pathogenic Clavibacter. Syst Appl Microbiol 2011, 34(6):400-407.

33. Jacques MA, Durand K, Orgeur G, Balidas S, Fricot C, Bonneau S, Quillévéré A, Audusseau C, Olivier V, Grimault V: Phylogenetic analysis and polyphasic characterization of Clavibacter michiganensis strains isolated from tomato seeds reveal that non-pathogenic strains are distinct from $C$. michiganensis subsp. michiganensis. Appl Environ Microbiol 2012, 78(23):8388-8402.

34. ISF: Methods for the detection of Clavibacter michiganensis ssp michiganensis on tomato seeds Version 4, 2011. http://www.worldseed.org/isf/ ishi_vegetable.html.

35. Jansing H, Rudolph K: Physiological capabilities of Clavibacter michiganensis subsp. sepedonicus and development of a semi-selective medium. Zeitschrift Fur Pflanzenkrankheiten Und Pflanzenschutz-Journal of Plant Diseases and Protection 1998, 105(6):590-601.

36. Pitcher D, Saunders N, Owen R: Rapid extraction of bacterial genomic DNA with guanidium thiocyanate. Lett Appl Microbiol 1989, 8(4):151-156.

37. Waleron M, Waleron K, Kamasa J, Przewodowski W, Lojkowska E: Polymorphism analysis of housekeeping genes for identification and differentiation of Clavibacter michiganensis subspecies. Eur J Plant Pathol 2011, 131(2):341-354.

38. Schneider KL, Marrero G, Alvarez AM, Presting GG: Classification of plant associated bacteria using RIF, a computationally derived DNA marker. PLoS One 2011, 6(4):e18496

39. Thompson J, Higgins D, Gibson T: CLUSTAL W: improving the sensitivity of progressive multiple sequence alignment through sequence weighting, position-specific gap penalties and weight matrix choice. Nucleic Acids Res 1994, 22(22):4673.

40. Altschul SF, Gish W, Miller W, Myers EW, Lipman DJ: Basic local alignment search tool. J Mol Biol 1990, 215(3):403-410.

41. Tamura K, Dudley J, Nei M, Kumar S: MEGA4: Molecular evolutionary genetics analysis (MEGA) software version 4.0. Mol Biol Evol 2007, 24(8):1596-1599.

42. Tamura K, Nei M: Estimation of the number of nucleotide substitutions in the control region of mitochondrial DNA in humans and chimpanzees. Mol Biol Evol 1993, 10(3):512-526.

43. Librado P, Rozas J: DnaSP v5: a software for comprehensive analysis of DNA polymorphism data. Bioinformatics 2009, 25(11):1451-1452. 
44. Hunter PR, Gaston MA: Numerical index of the discriminatory ability of typing systems: an application of Simpson's index of diversity. J Clin Microbiol 1988, 26(11):2465-2466.

45. Gelfand Y, Rodriguez A, Benson G: TRDB - the tandem repeats database. Nucleic Acids Res 2007, 35(suppl 1):D80-D87.

46. Rozen S, Skaletsky H: Primer3 on the WWW for general users and for biologist programmers. Methods Mol Biol 2000, 132(3):365-386.

47. Simpson EH: Measurement of diversity. Nature: Nature; 1949.

48. Nazari F, Niknam GR, Ghasemi A, Taghavi SM, Momeni H, Torabi S: An investigation on strains of Clavibacter michiganensis subsp. michiganensis in north and north west of Iran. J Phytopathol 2007, 155(9):563-569.

49. Klevytska AM, Price LB, Schupp JM, Worsham PL, Wong J, Keim P: Identification and characterization of variable-number tandem repeats in the Yersinia pestis genome. J Clin Microbiol 2001, 39(9):3179-3185.

50. Sobral D, Schwarz S, Bergonier D, Brisabois A, Feßler AT, Gilbert FB, Kadlec K, Lebeau B, Loisy-Hamon F, Treilles M: High Throughput Multiple Locus Variable Number of Tandem Repeat Analysis (MLVA) of Staphylococcus aureus from Human. Animal and Food Sources. PLoS One 2012, 7(5):e33967.

51. Call DR, Orfe L, Davis MA, Lafrentz S, Kang M-S: Impact of compounding error on strategies for subtyping pathogenic bacteria. Foodborne Pathog Dis 2008, 5(4):505-516.

52. Gulati P, Varshney R, Virdi J: Multilocus variable number tandem repeat analysis as a tool to discern genetic relationships among strains of Yersinia enterocolitica biovar 1A. J Appl Microbiol 2009, 107(3):875-884.

53. Broschat S, Call D, Davis M, Meng D, Lockwood S, Ahmed R, Besser T: Improved identification of epidemiologically related strains of Salmonella enterica by use of a fusion algorithm based on pulsed-field gel electrophoresis and multiple-locus variable-number tandem-repeat analysis. J Clin Microbiol 2010, 48(11):4072-4082.

54. Domenech P, Barry C 3rd, Cole ST: Mycobacterium tuberculosis in the post-genomic age. Curr Opin Microbiol 2001, 4(1):28.

55. Pourcel C, Minandri F, Hauck Y, D'Arezzo S, Imperi F, Vergnaud G, Visca P. Identification of variable-number tandem-repeat (VNTR) sequences in Acinetobacter baumannii and interlaboratory validation of an optimized multiple-locus VNTR analysis typing scheme. J Clin Microbiol 2011, 49(2):539-548.

56. Kremer K, Arnold C, Cataldi A, Gutierrez MC, Haas WH, Panaiotov S, Skuce RA, Supply P, van der Zanden AGM, van Soolingen D: Discriminatory power and reproducibility of novel DNA typing methods for Mycobacterium tuberculosis complex strains. J Clin Microbiol 2005, 43(11): 5628-5638.

\section{doi:10.1186/1471-2180-13-126}

Cite this article as: Zaluga et al:: Multilocus Variable-Number-TandemRepeats Analysis (MLVA) distinguishes a clonal complex of Clavibacter michiganensis subsp. michiganensis strains isolated from recent outbreaks of bacterial wilt and canker in Belgium. BMC Microbiology 2013 13:126.

\section{Submit your next manuscript to BioMed Central and take full advantage of:}

- Convenient online submission

- Thorough peer review

- No space constraints or color figure charges

- Immediate publication on acceptance

- Inclusion in PubMed, CAS, Scopus and Google Scholar

- Research which is freely available for redistribution 